\title{
Respiratory changes, hand fingers edema and yellow nails in a 94-year-old woman
}

\author{
Vitorino Modesto dos Santos, ${ }^{1,2}$ Christiane Aires Teixeira, ${ }^{3}$ Monique Chiovatto Montes Araújo, ${ }^{1}$ \\ Manoel da Costa Gondim Neto, ${ }^{1}$ Iara Machado Motta, ${ }^{1}$ Melissa Gebrim Ribeiro ${ }^{1}$ \\ ${ }^{1}$ Internal Medicine Department of Armed Forces Hospital, Brasília-DF; ${ }^{2}$ Catholic University Medical Course, Brasília-DF; \\ ${ }^{3}$ Pneumology Division of Armed Forces Hospital, Brasília-DF, Brazil
}

\begin{abstract}
A 94-year-old woman, with antecedent of chronic bronchitis, bronchiectasis, recurrent pneumonitis, arterial hypertension and chronic renal failure was admitted to control an episode of cardiac and respiratory insufficiency. Yellow nail changes and a tendency to pincer nails developed in her hand and toe fingers, preceded by longstanding course of respiratory diseases with pleural involvement. Laboratory tests detected moderate anemia and mildly elevated levels of urea and creatinine, thyroid function was normal. This case study is about yellow nail syndrome in the absence of ankle lymphedema, and affecting a woman of the oldest-old age group with renal failure.
\end{abstract}

\section{Introduction}

Yellow nail syndrome (YNS) has been considered a rare condition: ${ }^{1-12}$ however, at least in part, it seems to be under detected or underreported. ${ }^{3,4}$ YNS was first described by Samman and White in $1964 .{ }^{6}$ They reported this entity in a study on 13 patients, and most of them presented ankle edema and nails with slow growth. ${ }^{6}$ Although the classical triad of YNS includes yellowish discolored nails, lymphedema and pleural

Correspondence: Vitorino Modesto dos Santos, Armed Forces Hospital, Estrada do Contorno do Bosque s/n, Cruzeiro Novo, 70658-900, Brasília-DF, Brazil.

Tel.: +55.61.39662103 - Fax: +55.61.32331599.

E-mail: vitorinomodesto@gmail.com

Key words: Ankle lymphedema; chronic respiratory disease; yellow nail syndrome.

Acknowledgements: the authors would like to thank Almir José Batista, the official photographer of the Armed Forces Hospital, in Brasília-DF, Brazil for the images that illustrate the present case study.

Contributions: the authors contributed equally.

Received for publication: 27 March 2015.

Revision received: 27 March 2015.

Accepted for publication: 20 April 2015.

This work is licensed under a Creative Commons Attribution NonCommercial 4.0 License (CC BY-NC 4.0).

CC Copyright V. Modesto dos Santos et al., 2016

Licensee PAGEPress, Italy

Italian Journal of Medicine 2016; 10:140-142

doi:10.4081/itjm.2015.601 effusion, two of these changes are enough to establish the diagnosis. ${ }^{1-12}$ The etiology of YNS is not well clear, and the pathogenesis involves changes in lymphatic drainage. ${ }^{1-12}$ Lymphedema is the initial manifestation of YNS in approximately one-third of cases. The purpose of this study is to describe the syndrome in a woman of the oldest-old age group, presenting with distal hand finger edema and the absence of ankle lymphedema.

\section{Case Report}

A 94-year-old woman, with antecedent of pulmonary fibrosis, chronic bronchitis, bronchiectasis and arterial hypertension, was admitted to hospital with an acute episode of fever, continuous dyspnea, and cough with purulent sputum. One month before, she had been hospitalized with pneumonia and underwent antibiotic therapy. Currently, she was using candisartan, amlodipine, furosemide, atorvastatin, calcitriol, and omeprazole. She had always been a vegetarian and denied tobacco smoking and alcohol consumption. Physical examination showed body mass index: $26.13 \mathrm{~kg} / \mathrm{m}^{2}$; normal blood pressure, regular heart rhythm; non-pitting edema in hand fingers and absence of ankle edema; diffuse wheezing, and fine rales in the left medium third and at the base of both lung fields. Nail changes were seen, including inspissation, longitudinal ridging, hyper curvature, yellowish discoloration in toe fingers, and deficient lunula in hand fingers (Figure 1). Main laboratory determinations included hemoglobin: $10.7 \mathrm{~g} / \mathrm{dL}$, hematocrit: $32.3 \%$, leukocytes: $26,030 / \mathrm{mm}^{3}$, C-reactive protein: $24.3 \mathrm{mg} / \mathrm{dL}$, urea: $108.4 \mathrm{mg} / \mathrm{dL}$, creatinine: $2.5 \mathrm{mg} / \mathrm{dL}$, thyroid-stimulating hormone: $0.86 \mathrm{mcIU} / \mathrm{mL}$, free-T4: 
$1.15 \mathrm{ng} / \mathrm{dL}$, and negative blood cultures. Arterial gasometry determinations showed $\mathrm{pH}: 7.48, \mathrm{HCO}_{3}: 22.6$ $\mathrm{mmol} / \mathrm{L}$, base excess: $-0.5, \mathrm{PaCO}_{2}: 30.3 \mathrm{mmHg}, \mathrm{PaO}_{2}$ : $35.2 \mathrm{mmHg}, \mathrm{SaO}_{2}: 68.4 \%$, and anion gap: 4.3 $\mathrm{mmol} / \mathrm{L}$. Chest CT scan showed septal thickening, fibrosis, bronchiectasis, honeycombing, and small pulmonary nodules, in addition to basal areas with pleural thickening (Figure 2). Diagnoses of YNS and renal failure were based on clinical and complementary data. The patient was clinically managed with antibiotics to control respiratory infection. After hospital discharge, the patient was referred to Pneumology outpatient follow-up.

\section{Discussion}

The complete triad of YNS is reported in about one-third of patients; ${ }^{7}$ yellow nails occur in $89 \%$ of cases, lymphedema in $80 \%$, and pulmonary or pleural changes in $63 \% .{ }^{9}$ More frequently, pleural effusions are the last component of the syndrome to appear. ${ }^{9}$ Nevertheless, chronic rhinosinusitis, bronchitis, bronchiectasis, repeated pneumonitis, restrictive or obstructive pulmonary diseases, and pleural sequels are often reported. ${ }^{9}$ Letheulle et al., reported five

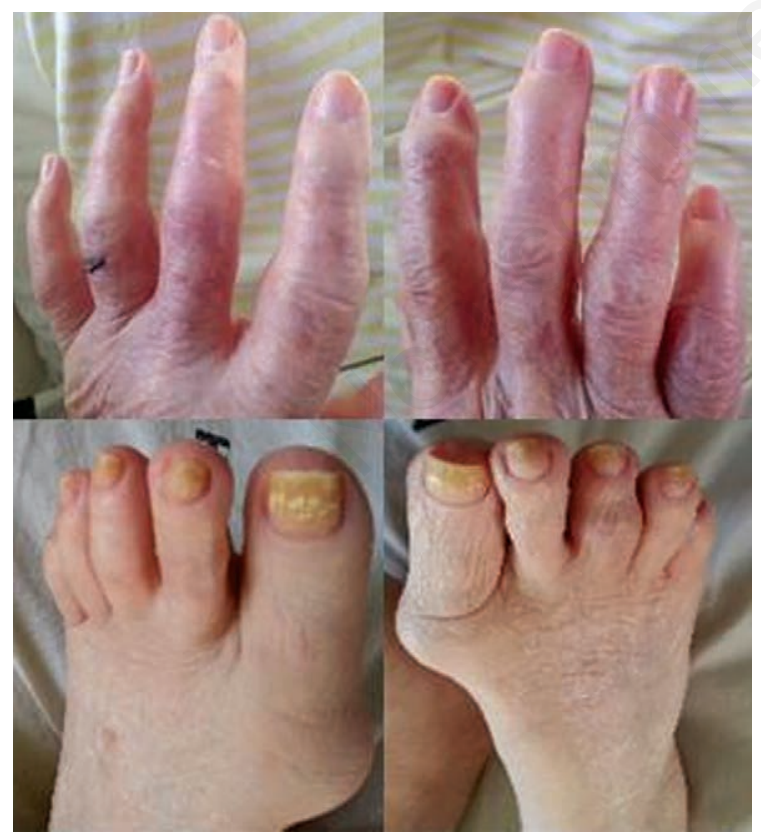

Figure 1. Swollen hands with indicative features of lymphedema, in association with nail changes typically found in cases of yellow nail syndrome - inspissations, longitudinal ridging, hyper curved nail plates and yellowish discoloration in toe fingers; deficient lunula is more evident in the hand fingers. Worthy of note is the moderate edema involving the hand fingers, and the absence of distal edema in the lower limbs. males with YNS, aged from 52 to 71 years, and median age of 56 years. Chronic sinusitis occurred in all patients; three had the triad and two did not have ankle lymphedema, but facial edema was observed..$^{10}$ Nordkild et al., reviewed 97 patients with YNS, most of them in early middle age, and with male/female ratio of $1 / 1.6$; yellow nails occurred in $99 \%$, lymphedema in $80 \%$, and respiratory changes in $63 \%$ of cases. ${ }^{11}$ Valdés et al., reviewed studies of 150 patients with diagnosis of YNS in a period of approximately 50 years, with male/female ratio of $1.2 / 1$, median age of 60 years and from birth to 88 years; $78 \%$ of patients were 41 to 80 years old. ${ }^{12}$ YNS and pleural effusions occurred mainly between the fifth to eighth decades of life, often associated with lymphedema. Although lymphedema was found in all the individuals with yellow nails plus pleural effusions, only $85.6 \%$ of the total group of patients presented with yellow nails. Bilateral pleural effusions occurred in $68.3 \%$ of the cases; moreover, the fluid was serous in $75.3 \%$, milky in $22.3 \%$ and purulent in $3.5 \% .{ }^{12}$ Pericardial effusions have been also described in YNS, and drainage may be needed..$^{7,12}$ Maldonado et al., analyzed 41 patients with YNS, 20 males and 21 females, with median age of 61 years and range from 18 to 82 years. Forty patients had chronic respiratory changes - pleural effusions (46\%), bronchiectasis (44\%), chronic sinusitis $(41 \%)$, and recurrent pneumonitis (22\%). Interestingly, 15 patients (37\%) had no lymphedema. ${ }^{7}$

In the patient herein described, non-pitting edema was observed exclusively in the upper extremities, involving all the hands fingers. This finding is not common in YNS, although some authors have described

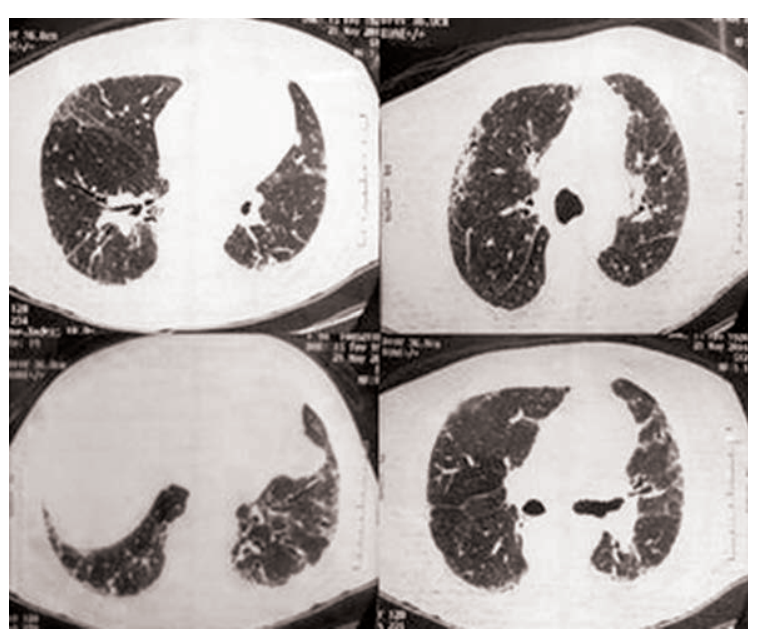

Figure 2. Computed tomography scan showing septal thickening, areas of fibrosis and multiple bronchiectasis, sparse foci of honeycombing at the periphery of the lungs, and small pulmonary nodules, in addition to basal areas with pleural thickening. 
lymphedema uniquely affecting the face. ${ }^{7,9}$ Chronic rheumatoid arthritis has been reported in association with the occurrence of YNS. ${ }^{8}$ Worthy of note, this patient had significant sequels of osteoarthritis in the upper extremities, which could have played a role in the origin of the well localized edema.

\section{Conclusions}

Incomplete triad of YNS may pose diagnostic challenges; however, higher index of suspicion about the main features of the syndrome lead to more accurate evaluation. The concomitance between hyper curved nails (pincer nails) and the yellowish discolored nails of the syndrome may follow either undiagnosed or scarcely reported.

\section{References}

1. dos Santos MV, Marques HV Jr, Lima Cdo C, et al. Yellow nail syndrome and adnexal tumour: causal or casual association? Indian J Chest Dis Allied Sci 2010;52:51-3.

2. Santos VM, Araújo MCM, Almeida ACA, et al. [Onychophagia, onychotyllomania and yellow nail syndrome in a 70-year-old woman.] Pren Med Argent 2013;99: 684-91.
3. Santos VM, Blanger V, Cançado ACV, et al. [An elderly woman with yellow nail syndrome and pincer nails]. Rev Med Saude Brasilia 2014;3:125-30.

4. Santos VM, Ribeiro KRA, Santos AMRO, et al. [Yellow nail syndrome in an old woman with hypothyroidism: a case report.]. Brasilia Med 2013;50:342-5.

5. Santos VM, Sá DAR, Paz BCS, et al. Half-and-half nails and yellow nail syndrome in hemiplegic patient with renal failure. Brasilia Med 2010;47:364-7.

6. Samman PD, White WF. The "yellow nail syndrome". Br J Dermatol 1964;76:153-7.

7. Maldonado F, Tazelaar HD, Wang CW, Ryu JH. Yellow nail syndrome: analysis of 41 consecutive patients. Chest 2008;134:375-81.

8. Mattingly PC, Bossingham DH. Yellow nail syndrome in rheumatoid arthritis: report of three cases. Ann Rheum Dis 1979;38:475-8.

9. Hershko A, Hirshberg B, Nahir M, Friedman G. Yellow nail syndrome. Postgrad Med 1997;73:466-8.

10. Letheulle J, Deslée G, Guy T, et al. [The yellow nail syndrome: a series of five cases]. Rev Maladies Resp 2012;29:419-25.

11. Nordkild P, Kromman-Andersen H, Struve-Christensen E. Yellow nail syndrome - the triad of yellow nails, lymphedema and pleural effusions. A review of the literature and a case report. Acta Med Scand 1986;219:221-7.

12. Valdés L, Huggins JT, Gude F, et al. Characteristics of patients with yellow syndrome and pleural effusion. Respirology 2014;19:985-92. 